\title{
Diverse Pseudomonas aeruginosa Gene Products Stimulate Respiratory Epithelial Cells to Produce Interleukin-8
}

Emily DiMango, Heather J. Zar, Ruth Bryan, and Alice Prince

Departments of Pediatrics and Medicine, College of Physicians and Surgeons, Columbia University, New York 10032

\begin{abstract}
Respiratory epithelial cells play a crucial role in the inflammatory response during Pseudomonas aeruginosa infection in the lungs of patients with cystic fibrosis. In this study, we determined whether the binding of specific Pseudomonas gene products ( pilin, flagellin) to their receptors on respiratory epithelial cells would result in production of the neutrophil chemoattractant IL-8. Piliated wild-type organisms, purified pili, or antibody to the pilin receptor (asialoGM1) evoked significant production of IL-8 by immortalized airway epithelial cells, whereas nonpiliated organisms were less able to bind to respiratory epithelial cells and stimulated much less IL-8 secretion $(P<0.01)$. A piliated, nonflagellated strain was also associated with decreased binding and a diminished level of IL-8 production when compared to wild-type organisms. Isogenic, nonadherent rpoN mutants, lacking pilin and flagellin, did not bind or elicit an IL-8 response. In addition, the IL-8 response was four-fold higher in a cystic fibrosis cell line compared with its corrected cell line. The Pseudomonas autoinducer, an exoproduct secreted during chronic infection, was found to stimulate IL-8 in a dose-dependent manner. $P$. aeruginosa adhesins, which are necessary for initial infection, directly stimulate IL-8 production by respiratory epithelial cells and therefore play a major role in the pathogenesis of Pseudomonas infection in patients with cystic fibrosis. The inflammatory response is subsequently perpetuated by Pseudomonas autoinducer which is secreted during chronic infection. ( $\mathrm{J}$. Clin. Invest. 1995. 96:2204-2210). Key words: Pseudomonas aeruginosa - adherence $\cdot$ interleukin-8 $\cdot$ pilin $\cdot$ autoinducer
\end{abstract}

\section{Introduction}

Infection with Pseudomonas aeruginosa is closely associated with the development and progression of pulmonary disease in cystic fibrosis $(\mathrm{CF}) .^{1}$ The features of this infection are unique to CF patients: environmental strains of Pseudomonas infect

Address correspondence to Alice Prince, Department of Pediatrics, College of Physicians and Surgeons, Columbia University, $650 \mathrm{~W}$. 168th Street, New York, 10032. Phone: 212-3056-4193; FAX: 212-305-2284; E-mail:asp7@columbia.edu.

Received for publication 16 February 1995 and accepted in revised form 2 August 1995.

1. Abbreviations used in this paper: CF, cystic fibrosis; CFTR, CF transmembrane regulator; Fla, flagellin; PAI, Pseudomonas autoinducer; Pil, pilin.

J. Clin. Invest.

(C) The American Society for Clinical Investigation, Inc.

0021-9738/95/11/2204/07 \$2.00

Volume 96, November 1995, 2204-2210 the CF respiratory tract and induce a florid host response characterized by the influx of neutrophils into the airway (1). Pilinmediated adherence to the airway epithelium is important in the initial stages of infection (2); however, in the chronic phases, the organisms no longer adhere directly to the epithelial cells, but remain superficial within the secretions of the airway lumen (3). The toxic effects of neutrophil components, elastase, oxygen radicals $(4,5)$, and the release of DNA and actin (6) all contribute to the formation of inspissated secretions and symptomatic pulmonary disease in CF. Chronic infection develops despite what appears to be a normal immune system.

The mechanisms by which the genetic defect in $\mathrm{CF}$ and the resultant abnormal cystic fibrosis transmembrane regulator (CFTR) (7) lead to chronic infection are not as yet fully delineated. Recent studies demonstrate that CF airway epithelial cell surfaces have a higher than normal concentration of asialylated glycolipids, to which $P$. aeruginosa pilin binds (8). This finding is consistent with data demonstrating that CFTR dysfunction, by limiting acidification within the trans Golgi, can result in diminished sialylation of cell glycoconjugates (9). Pseudomonas pilin binds to the increased asialoGM1 which is present on the CF epithelial cells, but not the sialylated form of this glycolipid that is found on normal cells (8).

We postulated that specific Pseudomonas gene products might directly elicit an inflammatory response by binding to asialylated glycolipid receptors and result in production of proinflammatory cytokines by the respiratory epithelium. To test this hypothesis, $P$. aeruginosa mutants defective in the expression of adhesins and/or specific exoproducts were tested for their ability to bind to epithelial cells and stimulate IL- 8 production, the major chemokine associated with neutrophil migration across the airway epithelium (10). This cytokine is found in increased amounts in the lungs of CF patients (11). Pilin, a major adhesin, as well as flagellin, each stimulated substantial IL-8 production. Moreover, a novel $P$. aeruginosa gene product, the Pseudomonas autoinducer (PAI), which is expressed in late stationary phase growth typical of chronic infection, also evoked an IL-8 response by epithelial cells.

\section{Methods}

Bacterial strains and culture conditions. The $P$. aeruginosa strains, listed in Table I (12-21) were grown with aeration in M9 media supplemented with glutamine as necessary. PAO/MP was grown in $\mathrm{M} 9+0.5 \%$ methionine assay medium (Difco Laboratories, Inc. Detroit, MI). PAO$\mathrm{R} 1$ (las $R$ ) contains an insertional mutation in las $R$, affecting the expression of PAI, elastase, alkaline protease, and neuraminidase $(20,22,23)$. $\mathrm{PAO} / \mathrm{NP}$ was constructed by allelic exchange in which the wild-type gene pilA was replaced by a homologous piece of DNA containing a tetracycline resistance $\left(\mathrm{Tc}^{\mathrm{R}}\right)$ cartridge within the coding sequence. The construction was confirmed by Southern hybridization and the phenotype documented by resistance to the pilus-specific phage F116 (24). Synthetic PAI and analogues of the autoinducer were generously provided by B. Iglewski, University of Rochester (Rochester, NY).

Bacterial cell fractionation and cell components. $P$. aeruginosa 


\begin{tabular}{|c|c|c|}
\hline Strain & Description & Source (Reference) \\
\hline PAK & Prototype, non-mucoid, laboratory strain & S. Lory \\
\hline $\mathrm{PAK} / \mathrm{NP}$ & $\mathrm{Pil}^{-}$constructed by gene replacement with pilA interrupted by a $\mathrm{Tc}^{\mathrm{R}}$ cassette & S. Lory $(12,13)$ \\
\hline PAK-N1 & $r p o N$ constructed by gene replacement & S. Lory (19) \\
\hline PAK/fliA & $\mathrm{Fla}^{-}$, constructed by gene replacement & S. Lory (14) \\
\hline PAO1 & Prototype, nonmucoid laboratory strain & G. Jacoby \\
\hline PAO1/DB2 & Hyperpiliated mutant & W. Paranchych (21) \\
\hline PAO/NP & $\mathrm{Pil}^{-}$, constructed by gene replacement as for PAK & This study \\
\hline AK1152 & $\mathrm{Fla}^{-}, \mathrm{Pil}^{+}, \mathrm{PAO}$ mutant isolated as nonmotile after chemical mutagenesis & T. Montie (16) \\
\hline PAO/MP & Pilin adhesin domain interrupted by the insertion of a CAT cassette & W. Paranchych (15) \\
\hline PAO-R1 & LasR $^{-}$, LasR interrupted by the insertion of $T c^{\mathrm{R}}$ marker & B. Iglewski (20) \\
\hline PAO/SRN & $\mathrm{PLC}^{-}$, insertional mutation in regulatory gene required for PLC expression & M. Vasil (18) \\
\hline PAO/ExoS & $\operatorname{ExoS}^{-}$, Insertional inactivation of regulatory gene required for exoenzyme $S$ expression & D. Frank (17) \\
\hline
\end{tabular}

components were isolated to determine which gene products are associated with IL-8 stimulation. Exoproducts were obtained by harvesting supernatants from organisms grown for $18 \mathrm{~h}$ in M9 media, concentrated 100 -fold with polyethylene glycol and dialyzed exhaustively versus phosphate buffer $\mathrm{pH}$ 7.4. Outer membrane proteins and periplasmic contents were isolated using standard methods $(25,26)$. Lipopolysaccharide from Escherichia coli and $P$. aeruginosa, neuraminidase from Vibrio cholera, and phospholipase $\mathrm{C}$ from Clostridium perfringens were commercially obtained (Sigma Chemical Co., St. Louis, MO). P. aeruginosa elastase was obtained from Nagase Chemical Co., (Tokyo, Japan).

Pili were isolated from the hyperpiliated PAO1 mutant DB2 using the method of Frost and Paranchych (21). In brief, DB2 was grown overnight on large M9 agar plates. The cells were scraped off, resuspended in SSC: $15 \%$ sucrose solution and filtered through a fine sieve to remove agar. The solution was stirred overnight at $4^{\circ} \mathrm{C}$ then pulsed at the lowest speed in a blender (Waring Commercial, New Hartford, CT) to shear off the pili. The cells were removed by centrifugation (SS34 8000 rpm for 20 min.; Sorvall Instruments Division, Newton, CT) and the supernatant was dialyzed against sterile water at $4^{\circ} \mathrm{C}$ for $16 \mathrm{~h}$. The pilin protein was precipitated with $50 \%$ ammonium sulfate at $4^{\circ} \mathrm{C}$ overnight and the resulting pellet dissolved in buffer. This was precipitated with $20 \%$ ammonium sulfate, resuspended in SSC-15\% sucrose and loaded on a discontinuous sucrose gradient, then centrifuged for $20 \mathrm{~h}$ at $4^{\circ} \mathrm{C}$ (SW27 rotor $20,000 \mathrm{rpm}, \mathrm{L} 7$ ultracentrifuge; Beckman Instruments, Inc., Fullerton, CA). The protein band was dialyzed and repurified on a $\mathrm{CsCl}$ gradient. The remaining protein was electrophoresed on an SDS-polyacrylamide gel and visualized with Coomassie blue as a single $15-\mathrm{kD}$ band. Antibody to pilin was obtained by rabbit inoculation (Pocono Rabbit Farm and Laboratory, Inc., Canadensis, PA) and negatively purified by repeated incubation with suspensions of $\mathrm{PAO} / \mathrm{NP}$ at $37^{\circ} \mathrm{C}$.

Flagellin isolation. Flagella from PAO/NP were isolated using the method of Montie et al. (27), and the band corresponding to $53 \mathrm{kD}$ was eluted into Tris $0.5 \mathrm{M}$ buffer. Purity was checked by SDS-polyacrylamide gel electrophoresis demonstrating a single 53-kD band.

IL-8 assays. 1HAEo- cells, SV40 immortalized human airway epithelial cells, whose epithelial properties have been well characterized (28), were assayed for the production of IL-8 in response to incubation with bacteria or bacterial components. Confluent monolayers of $1 \mathrm{HAE}-$ cells were grown in 96-well plates in DME-F12 containing fetal calf serum, and then serum starved for $18 \mathrm{~h}$ preceding stimulation. IB3 cells, an adeno-associated virus transformed human bronchial epithelial cell line derived from a patient with $C F(\triangle F 508 / W 1282 X)$, and the rescued line (C-38 cells) which expresses a plasmid encoded copy of a normal CFTR (29) were similarly grown to confluence in 96-well plates in LHC-8 media (Biofluids, Inc., Rockville, MD).

Bacteria were grown to late-log phase, washed, and resuspended in
PBS pH 7.4. An aliquot of $10^{7} \mathrm{CFU} / \mathrm{ml}$ of bacteria was incubated for $60 \mathrm{~min}$ at $37^{\circ} \mathrm{C}$ with a confluent monolayer of 1 HAEo- cells. The monolayers were washed three times with PBS and reincubated with $200 \mu \mathrm{l}$ DME-F12 containing $100 \mu \mathrm{g} / \mathrm{ml}$ of gentamicin for $18 \mathrm{~h}$. Bacterial supernatants were sterilized by the addition of gentamicin $40 \mu \mathrm{g} / \mathrm{ml}$ and similarly incubated with the epithelial cell monolayer for $1 \mathrm{~h}$. Comparable experiments were done using aliquots of the purified cell components, pili, flagella, and the commercially obtained exoproducts, all at concentrations of $10 \mu \mathrm{g} / \mathrm{ml}$. Protein concentrations were measured by the method of Bradford (Bio-Rad Laboratories, Richmond, CA). IL$1 \beta 20 \mathrm{ng} / \mathrm{ml}$ (R\&D Systems, Inc., Minneapolis, MN) was used as a positive control for stimulation of IL-8 from the epithelial cells. Antibody to asialoGM1 was purchased from Wako Pure Chemical Industries, Ltd. (Chuo-Ku, Japan) and was tested on the IB3 and C-38 cell lines. The integrity of the monolayer before IL- 8 assay was assessed by visualization, and cell viability after stimulation was confirmed by trypan blue exclusion. The uniformity of the monolayer was determined by quantifying the cell number/well.

IL-8 in the epithelial cell supernatant was assayed $18 \mathrm{~h}$ after stimulation by ELISA kit (R\&D Systems, Inc.) or by ELISA plates coated with mAb-IL-8 generously provided by Drs. I. Lindley and A. Rot (Sandoz, Vienna, Austria). IL-8 kinetics studies showed that peak IL8 production from 1 HAEo- cells occurs at 8-24 h after stimulation with $P$. aeruginosa (data not shown). Each data point was performed at least in duplicate, and each experiment was performed at least three times. Statistical analysis was performed using ANOVA analysis (Microsoft Excel 5.0 software; Microsoft Corp., Seattle, WA).

Northern blot analysis. 1HAEo- cells were analyzed for IL-8 gene expression $4 \mathrm{~h}$ after incubation with bacteria. Total cellular RNA was extracted by the single-step guanidium thiocyanate-phenol-chloroform extraction method ( 30 ) from $25-\mathrm{cm}^{2}$ culture flasks of confluent IHAEocells exposed either to control media or $P$. aeruginosa. The RNA pellet was precipitated with isopropanol, washed with $70 \%$ ethanol, vacuum dried, and redissolved in DEPC-treated water. Aliquots of $10 \mu \mathrm{g}$ total RNA (determined by spectrophotometry, 260-nm wavelength) were run on a denaturing formaldehyde $1 \%$ agarose gel. The RNA was transferred to a nylon membrane and UV crosslinked to the membrane. Filters were hybridized at $57^{\circ} \mathrm{C}$ with a ${ }^{32} \mathrm{P}$ end-labeled oligonucleotide probe with the sequence 5' GTT-GGC-GCA-GTG-TGG-TCC-ACT-CTC-AAT-CAC$3^{\prime}(31)$. Blots were washed twice for $60 \mathrm{~min}$ at $57^{\circ} \mathrm{C}$ in $2 \times \mathrm{SSC}$, then $0.5 \times \mathrm{SSC} / 1 \% \mathrm{SDS}$. To assess the relative amounts of RNA loaded, blots were rehybridized for glyceraldehyde 3-phosphate dehydrogenase (GAPDH) after stripping of the original probe.

Bacterial adherence assay. The number of $P$. aeruginosa adhering to the epithelial monolayers was quantified as has been previously described (8). The $P$. aeruginosa strains were grown to late log phase, metabolically labeled with ${ }^{35} \mathrm{~S}$ methionine, washed with $10 \mathrm{mM} \mathrm{NaCl}$ and a $0.1-\mathrm{ml}$ inoculum of $5 \times 10^{8} \mathrm{CFU} / \mathrm{ml}$ was added to each well of 


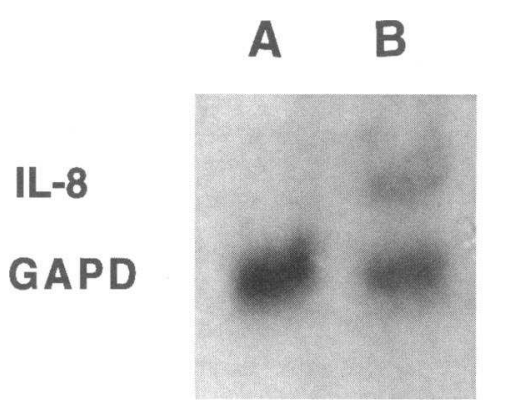

\section{$1.8 \mathrm{~Kb}$}

$1.3 \mathrm{~Kb}$

Figure 1. Northern blot analysis for IL-8 gene expression. 1. Control 1 HAEo- cells in serum free media; 2. 1HAEo- cells 4 hours after incubation with PAO1.

a confluent monolayer of the $1 \mathrm{HAEo}-$ cell line for $60 \mathrm{~min}$ at $37^{\circ} \mathrm{C}$ Nonadherent organisms were removed with three PBS rinses. The monolayers were solubilized in $200 \mu \mathrm{l}$ of $2 \%$ SDS and scintillations counted. Each point was performed in triplicate and a mean and standard deviation were determined.

\section{Results}

$P$. aeruginosa induces $I L-8$ gene expression. Northern blot analysis demonstrated IL-8 mRNA from epithelial cells exposed to $P$. aeruginosa PAO (Fig. 1). There was no evidence of endogenous IL-8 mRNA from control epithelial cells under the conditions used, in contrast to abundant amounts of mRNA specific for the constitutively expressed gene GAPDH.

Adherent $P$. aeruginosa elicit IL-8 production. The adherence of two different wild-type piliated strains of $P$. aeruginosa (PAK, PAO1) were compared (Fig. $2 \mathrm{~A}$ ). The more adherent strain, PAO1, evoked greater IL-8 expression by the epithelial monolayers (Fig. $2 \mathrm{~B}$ ) and relative adherence was found to correlate roughly with the relative amounts of IL- 8 produced by epithelial cells incubated with the organisms. The nonadherent rpoN mutant which expresses neither pili nor flagella and may be missing putative "nonpilus adhesins" $(19,32)$ did not elicit a detectable IL-8 response (Fig. 2, $A$ and $B$ ), suggesting that bacterial contact was important in triggering the IL-8 response. To determine if pilin itself was necessary for IL-8 stimulation, or if mere juxtaposition of the organisms was sufficient to allow a different gene product to come in contact with the epithelial cell, IL-8 assays were performed with several pil mutants as well as purified pilin.

Pilin evokes an $\mathrm{IL}-8$ response. $\mathrm{Pil}^{-}$mutants of PAO1 and PAK were significantly less adherent and less efficient in triggering IL-8 expression $(P<0.01)$ than the parental strains (Fig. 2, $A$ and $B$ ). PAO/MP, a PAO1 mutant with a $\mathrm{Cm}^{\mathrm{R}}$ cassette interrupting the carboxy terminus of the adhesin domain of the pilin, but otherwise normal pilin structure (15), was less adherent, correspondingly less effective in eliciting an IL8 response $(P<0.01)$, and was associated with IL-8 release virtually identical to that elicited by the $\mathrm{Pil}^{-}$mutant. The $\mathrm{Tc}^{\mathrm{R}}$ marker used to construct the $\mathrm{Pil}^{-}$strains $\mathrm{PAO} / \mathrm{NP}$ and PAK/ NP had no effect on the IL-8 response, as a control strain, $\mathrm{PAO} / \mathrm{SRN}$ with the identical $\mathrm{Tc}^{\mathrm{R}}$ marker in an irrelevant gene (phospholipase $\mathrm{C}$ ) had attachment and IL-8 stimulatory properties identical to that of the parental PAO1 (data shown below).

Purified pilin was demonstrated as a single band by Coomasie blue stain of SDS-PAGE, and confirmed by Western hybridization with antipilin antibody (Fig. 3). Pilin, when incubated
A

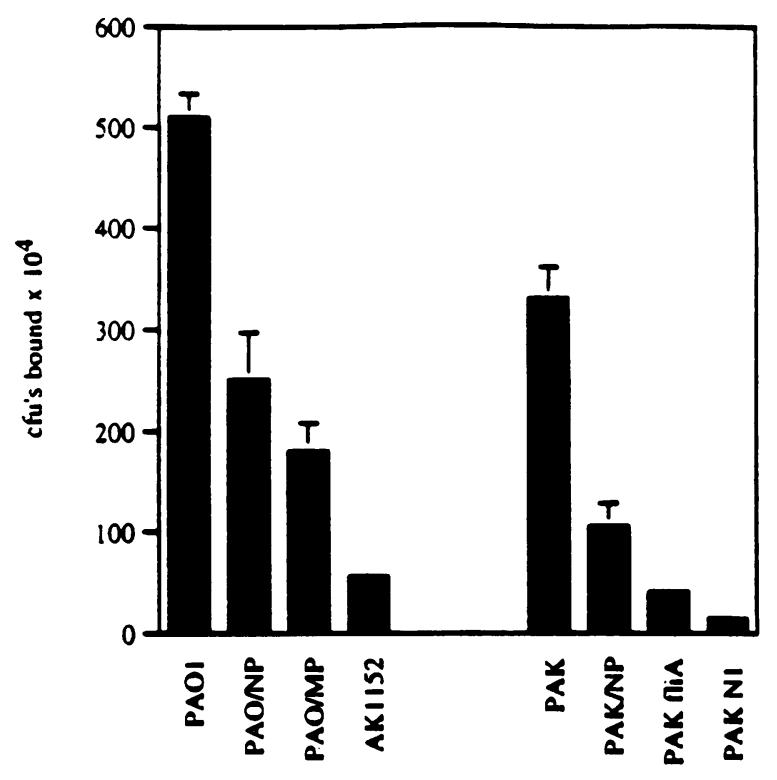

B

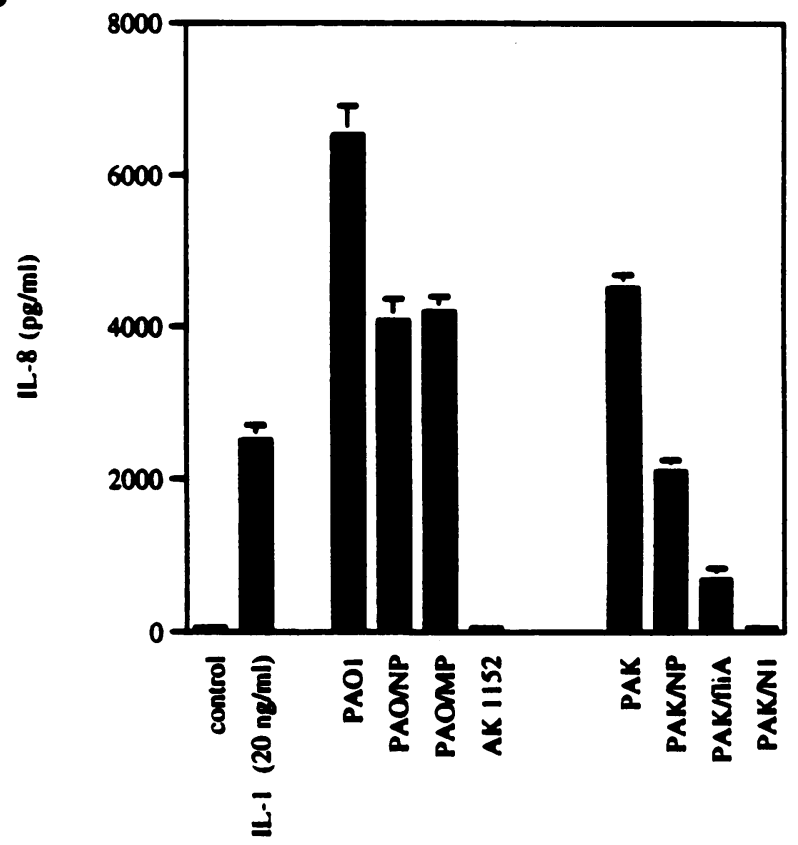

Figure 2. (A) Adherence of PAO1 and PAK to IHAEo- cells. PAO/ $\mathrm{NP}=\mathrm{PAO} / \mathrm{Pil}^{-} \mathrm{PAO} / \mathrm{MP}=\mathrm{PAO} /$ modified pilin; AK1152 $=\mathrm{PAO} /$ $\mathrm{Fla}^{-}$with dysfunctional pilin. PAK/NP $=\mathrm{PAK} / \mathrm{Pil}^{-} ; \mathrm{PAK} / \mathrm{fliA}$ $=\mathrm{PAK} / \mathrm{Fla}^{-} ; \mathrm{PAKN} 1=\mathrm{PAK} / \mathrm{RpoN}^{-}$. $(B) \mathrm{IL}-8$ expression by IHAEo - cells after stimulation with above strains. Control is IHAEocells in basal state; IL-1 $\beta(20 \mathrm{ng} / \mathrm{ml})$ - positive control. (Some of the error bars are contained within the data points).

with the IHAEo- cells demonstrated a dose-response effect in stimulating IL-8 production (Fig. 4). Cytochalasin D in various concentrations $(0.2-0.25 \mu \mathrm{g} / \mathrm{ml})$ had no effect on the amount of IL-8 produced under these conditions (data not shown), 


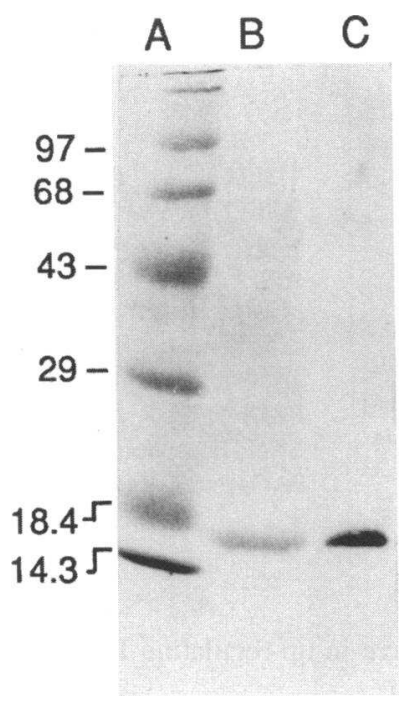

Figure 3. Pilin used for epithelial stimulation. (A) Molecular mass markers; (B) Coomassie blue-stained SDSPAGE; $(C)$ Western hybridization using antipilin antisera. thus it is unlikely that epithelial uptake of pilin mediated by cytoskeleton components is involved in the IL-8 response.

Cell fractionation studies demonstrated that the outer membrane protein (OMP) fraction had the highest activity, but other cell compartments also triggered IL-8 production although to a lesser extent (Fig. 5). LPS did not elicit IL-8 from the epithelial cell.

$C F$ cells produce more $I L-8$ in response to $P A O 1$. We postulated that pili act superficially on the epithelial surface by binding to their receptor, a GalNAc $\beta 1-4 \mathrm{Gal}$ moiety found in asialylated lipids such as asialoGM1 (8). As CF cells have significantly more asialoGM1 available on their cell surfaces, a CF cell line (IB3) and the corrected isogenic line (C-38), were compared for their ability to produce IL-8 in response to incubation with PAO1 (Fig. 6). PAO1 triggered four-fold greater IL8 expression from the CF cells as compared with the corrected cells $(P<0.05)$. Antibody (1:32 dilution) directed against asialoGM1, the pilin receptor, was as effective as PAO1 in eliciting IL-8 expression from the CF cells. The corrected cell line was refractory to stimulation by the identical amount of antibody (Fig. 6), suggesting that the appropriate receptors were unavailable on the corrected cells. This is consistent with the reported $86 \%$ increased binding of PAO1 to these CF cells as compared with the corrected cells (33).

Flagellin and IL-8 production. Nonpiliated mutants of $P$. aeruginosa were capable of triggering an IL-8 response, albeit reduced, suggesting that other gene products are also capable
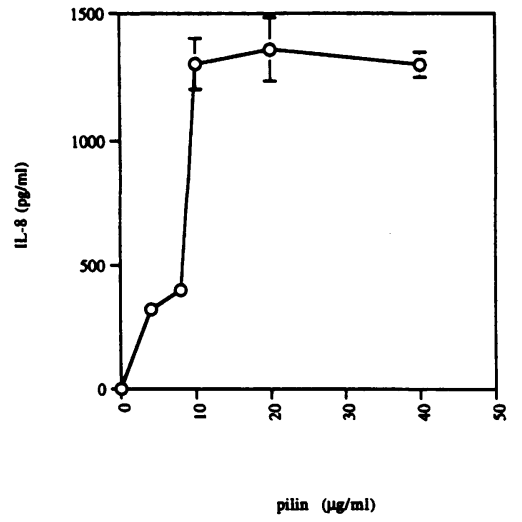

Figure 4. IL-8 production by IHAEo- cells in response to increasing concentrations of pilin.

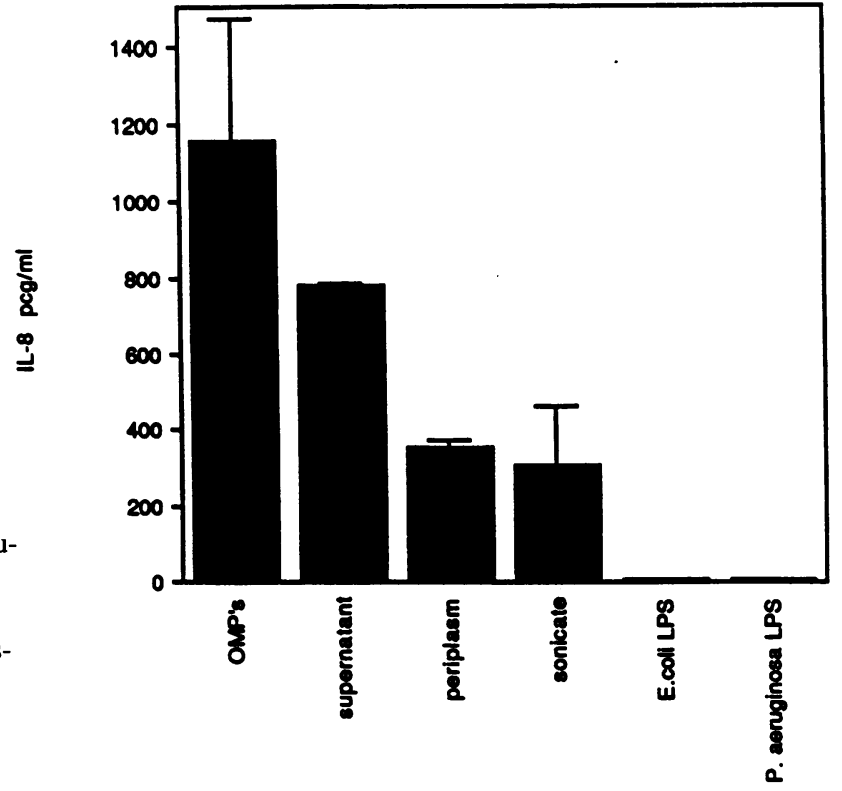

Figure 5. IL-8 production stimulated by bacterial components. The amount of IL-8 produced after incubation with PAO1 cell fractions (10 $\mu \mathrm{g} / \mathrm{ml})$ or LPS (10 $\mu \mathrm{g} / \mathrm{ml})$. OMP, outer membrane proteins.

of IL-8 stimulation. Recent reports suggest that flagellin can function as an adhesin and recognizes the same GalNAc $\beta 1$ $4 \mathrm{Gal}$ receptor as pilin (34). To determine if flagellin can elicit an IL-8 response, the $\mathrm{Fla}^{-}$mutants AK1152 (PAO) and PAK/ fliA were studied (Fig. 2). AK1152 was poorly adherent and unable to stimulate detectable levels of IL-8. Although this strain does produce pilin as determined by Western hybridization (data not shown), it was resistant to the pilus-dependent phage F116 and does not produce functional, retractile pili. The PAK/ fliA strain had intermediate levels of attachment and corresponding efficiency in evoking IL-8 expression (Fig. 2). Purified flagellin, demonstrated as a single band on Coomassie stain of SDS-PAGE (Fig. 7), was applied to the epithelial cells and stimulated a dose-dependent IL-8 response which was actually greater on a molar basis, than the pilin response (Fig. 8). These experiments suggest that flagellin contributes to the IL-

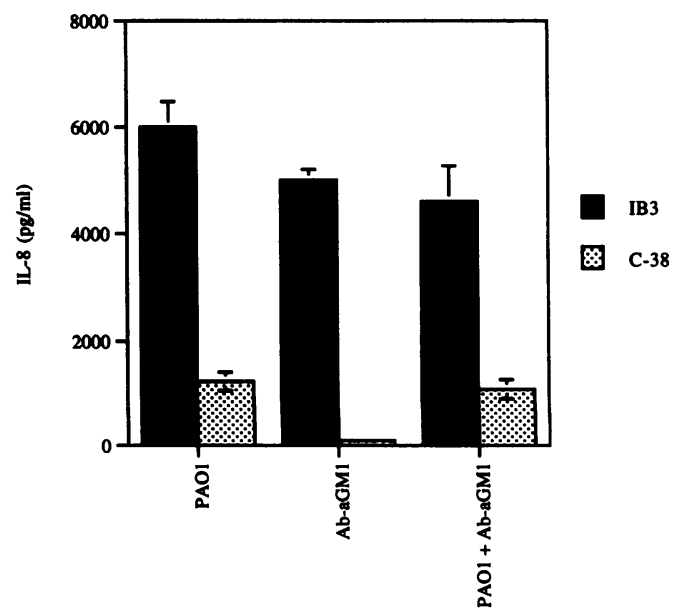

Figure 6. Comparison of IL-8 production by IB3 (CF) and C-38 (corrected) cells incubated with PAO1, polyclonal Ab-aGM1, and PAO1 $\left(10^{7} \mathrm{CFU} / \mathrm{ml}\right)$ plus Ab-aGM1. 


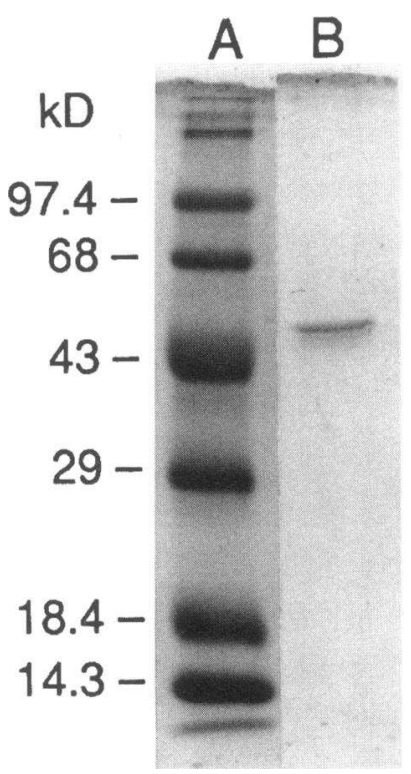

Figure 7. Flagellin used for epithelial cell stimulation. (A) Molecular mass markers; $(B)$ Coomassie blue-stained SDS-PAGE.

8 response not only by providing motility for the organism, but also by serving as an adhesin for epithelial attachment. Thus, two bacterial components which recognize superficial receptors on epithelial cells trigger IL-8 expression.

$P$. aeruginosa exoproduct $P A I$ elicits an $I L-8$ response. $P$. aeruginosa express a number of enzymes that modify eukaryotic targets. Human proteases such as neutrophil elastase stimulate IL-8 production (4), suggesting that $P$. aeruginosa proteases might have analogous effects. Mutants with defective expression of specific exoproducts were compared for their ability to stimulate IL-8. Neither the phospholipases nor exoenzyme $S$ appear to contribute to IL-8 production as the PAO/SRN $\left(\mathrm{PLC}^{-}\right)$and $\mathrm{PAO} /$ ExoS were even more efficient than the parental strain in evoking an IL-8 response (Fig. 9). PAO-R1, however, was significantly impaired in its stimulatory activity $(P<0.01)$. This strain has a mutation in las $R$ affecting the production of PAI, a homoserine lactone derivative which is a diffusible molecule acting as a cofactor for the transcriptional activator LasR. This molecule is involved in the expression of several genes such as elastase, alkaline protease, and neuraminidase. Purified elastase and neuraminidase had no stimulatory effect on the monolayers (data not shown). However, synthetic autoinducer had a dose-response effect in evoking IL-8 production by the 1HAEo- cells (Fig. 10). Control compounds, homoserine lactone derivatives with very minor changes in the

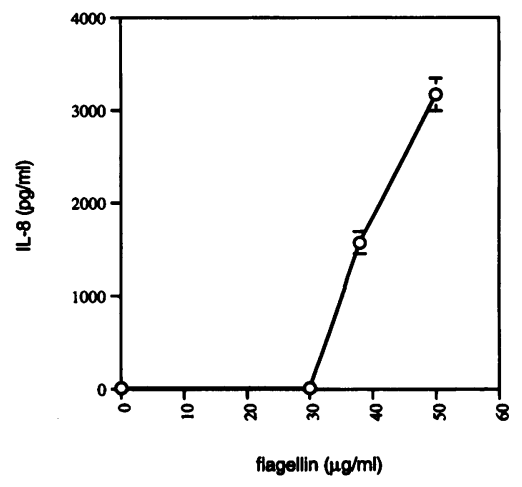

Figure 8 . IL-8 production by IHAEo- cells in response to increasing concentrations of flagellin.

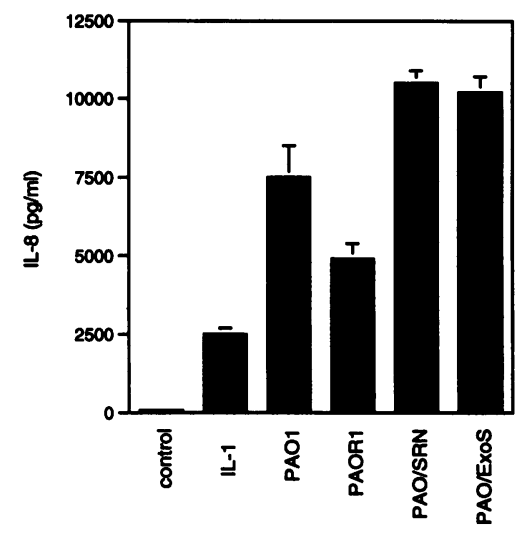

Figure 9 . IL-8 production by IHAEo - cells in response to incubation with PAO1 mutants. (Control), 1HAEocells in media; IL- $1 \beta(20$ $\mathrm{ng} / \mathrm{ml})$, positive control PAOR1, LasR $^{-}$; PAO/ SRN, Phospholipase C; PAO/ExoS, Exoenzyme $S^{-}$.

molecular structure, were ineffective in up-regulating IL-8 expression (Fig. 10, insert).

PAI effect on the 1HAEO - cells was very similar to that described by other investigators who found that a small $(<1$ $\mathrm{kD}$ ) molecular mass compound isolated from late stationary phase culture supernatants of a nonadherent strain of $P$. aeruginosa, PA103, was capable of IL-8 stimulation (35). This reported compound is water soluble and heat stable, characteristics consistent with PAI. The amount of IL- 8 expressed by the 1 HAEo- cells $\left(6.6 \times 10^{4} \pm 3.2 \times 10^{3}\right.$ cells/well $)$ after incubation with PAI, when expressed as a function of the DNA content, was equivalent to $736 \mathrm{pg} / \mu \mathrm{g}$ of DNA. This is approximately one order of magnitude higher than the reported IL-8 concentration detected by incubation of a different cell line (16HAEo- cells) with the small molecular weight compound isolated by Maisson et. al. (35).

\section{Discussion}

As with many infectious diseases, it is the type and severity of the host inflammatory response which is mainly responsible for the clinical outcome. Abundance of inflammatory mediators and products of polymorphonuclear leukocytes are found within the

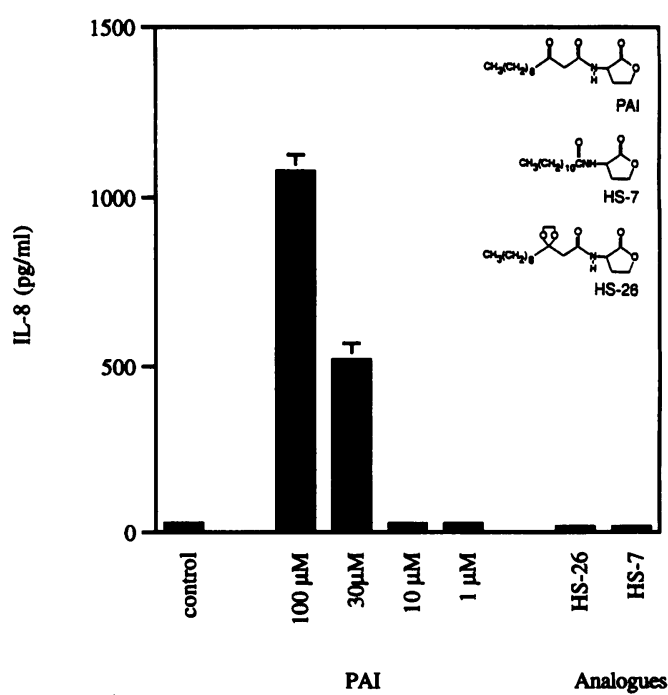

Figure 10. IL-8 production by IHAEo- cells in response to increasing amounts of synthetic Pseudomonas autoinducer and homoserine lactone analogues. Inset shows the structure of PAI and the two analogues. 
bronchial tree of CF patients (11). Even young children $(<1$ yr old) with CF, without clinically apparent lung disease, have $P$. aeruginosa isolated from pulmonary secretions (Ramsey, B., and A. Smith CFF-Research Development Program, unpublished data), indicating that $\mathrm{CF}$ patients have inherent elevated affinity for $P$. aeruginosa infection. It has been unclear why these organisms, and rarely other opportunistic pathogens, are so specifically linked to the pulmonary pathology in CF. Availability of asialyated glycolipid receptors for $P$. aeruginosa adhesins on the CF epithelium may serve not only to provide a niche for attachment but also to initiate a self-perpetuating inflammatory response which ultimately results in the destruction of the CF lung.

During the earliest stages of infection of the CF lung, when $P$. aeruginosa is transiently inspired but not cleared by the usual muco-ciliary mechanisms, they may attach via pili to the GalNAc $\beta 1-4 \mathrm{Gal}$ receptors found in significantly increased numbers in $C F$ patients, especially those homozygous for the $\Delta 508$ mutation in CFTR (36). The experiments reported here demonstrate that this $P$. aeruginosa binding, as mediated by pili and/or flagella, triggers IL-8 production by respiratory epithelial cells. In fact, IL-8 production elicited by various mutants parallels the adherence pattern of the mutants. IL-8 expression is followed by the infiltration of PMN's whose elaboration of superoxide and elastase serve to further stimulate the epithelium to produce IL-8 (4). This cycle of inflammation persists during later stages of infection when organisms may no longer express pili or flagella and may not even be directly apposed to the epithelium, but are enmeshed in relatively inert microcolonies surrounded by glycoconjugates of both bacterial and human origin. Under these conditions exoproducts such as the PAI would be secreted by $P$. aeruginosa and continue to evoke IL8 expression.

Pilin-mediated adherence is an important stimulus for $\mathrm{IL}-8$ production by the epithelium. Nonpiliated mutants were significantly impaired in their ability to trigger IL-8, as were mutants with genetically modified, dysfunctional, pilin adhesin domains. Moreover, antibody to the pilin receptor was effective in eliciting an IL-8 response specifically from CF cells which have increased numbers of available receptor sites. These findings suggest that the nonspecific binding of $P$. aeruginosa, as mediated by nonpilus (and nonflagellar) adhesins may not be associated with as significant pathology. Recent studies using a neonatal mouse model of acute pneumonia have demonstrated that purified pilin specifically induces polymorphonuclear leukocyte-dominated airway inflammation, consistent with an IL8-mediated response (2).

The precise role of flagella in the pathogenesis of respiratory tract infection is less clear. Flagella confers motility to the organism, therefore, nonmotile strains may have less ability to find an appropriate binding site. $\mathrm{Fla}^{-}$mutants including the strain used here, AK1152, have been demonstrated in other models of infection to be less virulent (16). In addition, it appears that flagellin can act as an adhesin, as inferred from the studies presented here as well as the data of Gehring and Baker (34). Flagellin also contributes to the ability of $P$. aeruginosa to elicit an inflammatory response. This was best illustrated by the results obtained with $\mathrm{AK} 1152$, the $\mathrm{Pil}^{-}, \mathrm{Fla}^{-}$mutant which was unable to bind and unable to stimulate IL-8, suggesting that flagellin may account for the pilin-independent attachment and IL-8 stimulation associated with PAO/NP ( $\mathrm{Pil}^{-}$, $\mathrm{Fla}^{+}$). PAK-N1 the rpoN mutant which is defective in the expression of several genes requiring the alternative $o^{54}$ RNA polymerase, is nonadherent and unable to stimulate an IL-8 response. Other $r p o N$-dependent genes have been postulated to act as "nonpilus adhesins" that recognize receptors in mucins or other glycoproteins (19). Such adhesins do not appear to be involved in these interactions with epithelial cells. The data presented here suggest that pili and flagella are the major $P$. aeruginosa gene products which interact with the available receptors on the epithelial cell surface to confer attachment and elicit IL-8 release.

The binding process may also serve to facilitate the juxtaposition of additional bacterial component(s) which elicit IL-8 expression. Our data has identified only PAI as a major secreted effector in stimulating an IL-8 response. The earlier report by Massion et al. is also consistent with a single active compound that is not a protein and is present in the cell supernatant. PAI concentration is dependent on bacterial concentration, and would be high in a chronically infected lung with dense bacterial growth. As a small, hydrophobic, highly permeant molecule, PAI is likely to act on the epithelium in a manner distinct from that of pili and flagella and may recognize an intracellular target in eukaryotes.

It is likely that at least two independent mechanisms are operative in the epithelium to activate IL-8 expression; one which involves a superficial event as initiated by pilin (or flagellin) binding to its asialylated receptor and another mechanism which is stimulated by PAI. Unlike the macrophage the respiratory epithelial cell does not express IL-8 in response to LPS, a generic signal of gram-negative organisms. Pilin stimulation of IL-8 production by these respiratory cells may be similar to IL-8 production by other mucosal cells that can be superficially infected by adherent, noninvasive organisms; for example, uroepithelial cells express IL-8 after piliated $E$. coli adhere, but not after random interactions with nonpiliated organisms (37). This process is somewhat different from the cytochalasininhibitable IL-8 expression elicited from T84 cells after organisms such as Salmonellae actually invade the cells (38) because it is not inhibited by cytochalasin and it doesn't require invasion. $P$. aeruginosa behave more like the uropathogenic $E$. coli in that superficial attachment to the epithelium is sufficient to trigger IL-8 synthesis and, as in the uroepithelium, a novel pathway of signal transduction, perhaps via ceramide or gangliosidemediated binding, may be involved (39).

The observed epithelial secretion of $\mathrm{IL}-8$ in response to contact with $P$. aeruginosa and specific exoproducts provides an important link to explain the pathogenesis of Pseudomonas infection in CF. Increased Pseudomonas attachment is a consequence of abnormal CFTR function; diminished acidification in the trans-Golgi and consequently diminished sialyltransferase activity results in more asialylated receptors for $P$. aeruginosa pili (8). The biological consequence of increased GalNAc $\beta 1$ $4 \mathrm{Gal}$ receptors is excessive stimulation of $\mathrm{IL}-8$ secretion in response to infection with $P$. aeruginosa. Asialo receptors are triggered by Pseudomonas binding, an event which is unlikely in the normal, fully sialylated epithelium but would have a much greater probability of occurring in the CF host. The degree of persistent infection and inflammation would then fluctuate depending upon continued synthesis of bacterial factors such as PAI, viral superinfections, and the immunologic response to these exogenous as well as endogenous mediators. Strategies to block the GalNAc $\beta 1-4 \mathrm{Gal} P$. aeruginosa pilin receptor exposed on the $C F$ epithelium may be useful to prevent the initial inflammatory response in the $\mathrm{CF}$ lung and the ensuing activation of neutrophils. 


\section{Acknowledgments}

We thank Q. Al-Awqati and B. Iglewski for suggestions and assistance D. Gruenert for providing $1 \mathrm{HAEO}-$ cells, P. Zeitlen for providing IB3 and C-38 cells, and L. Passador for the synthetic PAI and analogues.

This work was supported by the Cystic Fibrosis Foundation (H. J. Zar), the CFF-Research Development Program at Columbia University (A. Prince), by U.S. Public Health Service grant DK39693 (A. Prince) and by the New York Lung Association (E. DiMango).

\section{References}

1. McElvaney, N. G., H. Nakamura, B. Birrer, C. A. Hebert, W. L. Wong M. Alphonso, J. B. Baker, M. A. Catalano, and R. G. Crystal. 1992. Modulation of airway inflammation in cystic fibrosis. J. Clin. Invest. 90:1296-1301.

2. Tang, H. B. M. Kays, and A. S. Prince. 1995. The role of pili in the development of acute Pseudomonas aeruginosa respiratory tract infection of the neonatal mouse. Infect. Immun. 63:1278-1285.

3. Baltimore, R. S., C. D. C. Christie, and G. J. Walker-Smith. 1989. Immunohistopathologic localization of Pseudomonas aeruginosa in lungs from patients with cystic fibrosis. Am. Rev. Respir. Dis. 140:1650-1661.

4. Nakamura, H., K. Yoshimura, N. G. McElvaney, and R. G. Crystal. 1992. Neutrophil elastase in respiratory epithelial lining fluid of individuals with cystic fibrosis induces interleukin- 8 gene expression in a bronchial epithelial cell line. J. Clin. Invest. 89:1478-1484.

5. Standiford, T. J., S. L. Kunkel, M. A. Basha, S. W. Hensue, J. P. Lynch III, G. B. Toews, J. Westwick, and R. M. Strieter. 1990. Interleukin-8 gene expression by a pulmonary epithelial cell line. J. Clin. Invest. 86:1945-1953.

6. Vasconcellos C. A., P. G. Allen, M. E. Wohl, J. M. Drazen, P. A. Janmey, and T. P. Stossel. 1994. Reduction in viscosity of cystic fibrosis sputum in vitro by gelsolin. Science (Wash. DC). 263:969-971.

7. Welsh, M. J., and A. E. Smith. 1993. Molecular mechanisms of CFTR chloride channel dysfunction in cystic fibrosis. Cell. 73:1251-1254.

8. Saiman, L., and A. Prince. 1993. Pseudomonas aeruginosa pili bind to asialoGM1 which is increased on the surface of cystic fibrosis epithelial cells. $J$. Clin. Invest. $92: 1875-1880$

9. Barasch, J., B. Kiss, A. Prince, L. Saiman, D. Gruenert, and Q. Al-Awqati 1991. Defective acidification of intracellular organelles in cystic fibrosis. Nature (Lond.). 352:70-73.

10. Huber, A. R., S. J. Kunkel, R. F. Todd, and S. J. Weiss. 1991. Regulation of transendothelial neutrophil migration by endogenous interleukin-8. Science (Wash. DC). 254:99-102.

11. Dean, T. P., Y. Daij, J. K. Shute, M. K. Church, and J. O. Warner. 1993 Interleukin-8 concentrations are elevated in bronchoalveolar lavage, sputum, and sera of children with cystic fibrosis. Pediatr. Res. 34:159-161.

12. Ramphal, R., L. Koo, K. Ishimoto, P. A. Totten, J. D. Lara, and S. Lory 1991. Adhesion of Pseudomonas aeruginosa pilin-deficient mutants to mucin Infect. Immun. 9:1307-1311.

13. Saiman, L., K. Ishimoto, S. Lory, and A. S. Prince. 1990. The effect of piliation and exoproduct expression on the adherence of Pseudomonas aeruginosa to respiratory epithelial monolayers. J. Infect. Dis. 161:541-548.

14. Starnbach, M. N., and S. Lory. 1992. The fliA (rpoF) of Pseudomonas aeruginosa encodes an alternative sigma factor required for flagellin synthesis. Mol. Microbiol. 6:459-469.

15. Farinha, M. A., B. D. Conway, L. M. G. Glasier, N. W. Ellert, R. T Irvin, R. Sherburne, and W. Paranchych. 1994. Alteration of the pilin adhesin of Pseudomonas aeruginosa PAO results in normal pilus biogenesis but a loss of adherence to human pneumocyte cells and decreased virulence in mice. Infect. Immun. 62:4118-4123.

16. Drake, D. and T. C. Montie. 1988. Flagella, motility and invasive virulence of Pseudomonas aeruginosa. J. Gen. Microbiol. 134:43-52.

17. Frank, D. W., G. Nair, and H. P. Schweizer. 1994. Construction and characterization of chromosomal insertional mutations of the Pseudomonas aeruginosa exoenzyme S trans-regulatory locus. Infect. Immun. 62:554-563.
18. Ostroff, R. M., B. Wretllind, and M. L. Vasil. 1989. Mutations in the hemolytic-phospholipase C operon result in decreased virulence of Pseudomonas aeruginosa PAO1 grown under phosphate-limiting conditions. Infect. Immun. 57:1369-1373.

19. Simpson, D. A., R. Ramphal, and S. Lory. 1992. Genetic analysis of Pseudomonas aeruginosa adherence: distinct genetic loci control attachment to epithelial cells and mucins. Infect. Immun. 60:3771-3779.

20. Gambello, M. J., and B. H. Iglewski. 1991. Cloning and characterization of the Pseudomonas aeruginosa lasR gene, a transcriptional activator of elastase expression. J. Bacteriol. 173:3000-3009.

21. Frost, L. S., and W. Paranchych. 1977. Composition and molecular weight of pili purified from Pseudomonas aeruginosa. J. Bacteriol. 131:259-269.

22. Pearson, J. P., K. M. Gray, L. Passador, K. D. Tucker, A. Eberhard, B. H. Iglewski, and E. P. Greenberg. 1994. Structure of the autoinducer required for expression of Pseudomonas aeruginosa virulence genes. Proc. Natl. Acad. Sci. USA. 91:197-201.

23. Cacalano, G. S., M. Kays, L. Saiman, and A. Prince. 1992. Production of the Pseudomonas aeruginosa neuraminidase is increased under hyperosmolar conditions and is regulated by genes involved in alginate expression. J. Clin. Invest. 89:1866-1874.

24. Pemberton, J. M. 1973. F116: a DNA bacteriophage specific for the pil of Pseudomonas aeruginosa strain PAO. Virology. 55:558-560.

25. Hancock, R. E. W., and H. Nikaido. 1978. Outer membranes of gramnegative bacteria. J. Bacteriol. 136:381-390.

26. Witholt, B., M. Boekhout, M. Brock, J. Kingma, H. van Heerikhuizen, and L. deLeij. 1976. An efficient and reproducible procedure for the formation of spherolasts from variously grown E. coli. Anal. Biochem. 74:160-170.

27. Allison, J. S., M. Dawson, D. Drake, and T. C. Montie. 1985. Electrophoretic separation and molecular characterization of Pseudomonas aeruginosa $\mathrm{H}$ antigen flagellins. Infect. Immun. 49:770-774.

28. Gruenert, D. C., C. B. Basbaum, M. J. Welsh, W. E. Finkbeiner, and J. A Nadel. 1988. Characterization of human tracheal epithelial cells transformed by an origin defective simian virus 40. Proc. Natl. Acad. Sci. USA. 85:5951-5955.

29. Flotte, T. R., S. A. Afione, C. Conrad, S. A. McGrath, R. Solow, H. Oka P. Zeitlin, W. B. Guggino, and B. J. Carter. 1993. Stable in vivo expression of the cystic fibrosis transmembrane conductance regulator with an adeno-associated virus vector. Proc. Natl. Acad. Sci. USA. 90:10613-10617.

30. Chirgwin, J. M., A. E. Przybyla, R. J. MacDonald, and W. J. Rutter. 1979. Isolation of biologically active ribonucleic acid from sources enriched in ribonuclease. Biochemistry. 18:5294-5299.

31. DeForge, L. E., A. M. Preston, E. Takeuchi, J. Kenney, L. A. Boxer and D. G. Remick. 1993. Regulation of Interleukin 8 gene expression by oxidant stress. J. Biol. Chem. 286:25568-25576.

32. Ishimoto, K. S., and S. Lory. 1989. Formation of pilin in Pseudomonas aeruginosa requires the alternative sigma factor $(r p o N)$ of RNA polymerase. Proc. Natl. Acad. Sci. USA. 86:1954-1957.

33. Imundo, L., J. Barasch, A. Prince, and Q. Al-Awqati. 1995. Cystic fibrosis epithelial cells have a receptor for pathogenic bacteria on their apical surface. Proc. Natl. Acad. Sci. USA. 92:3019-3023.

34. Gehring, K., and N. R. Baker. 1994. Evidence for a role of flagella in the binding of Pseudomonas aeruginosa to glycosphingolipid receptors D-134 American Society for Microbiology, Las Vegas, NV. (Abstr.)

35. Massion, P., H. Inoue, J. Richman-Eisenstat, D. Grunberger, P. G. Jorens, B. Houssel, J. P. Wiener-Kronish, and J. Nadel. 1994. Novel Pseudomonas product stimulates interleukin-8 production in airway epithelial cells in vitro. J. Clin. Invest. 93:26-32.

36. Zar, H., L. Saiman, L. Quittell, and A. S. Prince. 1995. The binding of Pseudomonas aeruginosa to respiratory epithelial cells from cystic fibrosis patients with various mutations in CFTR. J. Pediatr. 126:230-233.

37. Agace, W. W., S. R. Hedges, M. Ceska, and C. Svanborg. 1993. Interleukin-8 and the neutrophil response to mucosal gram-negative infection. J. Clin. Invest. 92:780-785.

38. Eckmann L., M. F. Kagnoff, and J. Fierer. 1993. Epithelial cells secrete the chemokine interleukin- 8 in response to bacterial entry. Infect. Immun. 61:4569-4574.

39. Kolesnick, R., and D. W. Golde. 1994. The sphingomyelin pathway in tumor necrosis factor and interleukin-1 signaling. Cell. 77:325-328. 